\title{
Using a Journal Article with Sophomores to Increase Lifelong Learning Con- fidence
}

\section{Dr. Laura P Ford, University of Tulsa}

Dr. Laura Ford is an Associate Professor of Chemical Engineering at the University of Tulsa. She teaches engineering science thermodynamics and fluid mechanics, mass transfer, and senior labs. Her research areas are vacuum etching of copper from photovoltaic materials and formation, characterization, and prevention of natural gas hydrates. 


\section{Using a Journal Article with Sophomores to Increase Lifelong Learning Confidence}

Introduction

Journal articles are often used in upper-level engineering courses as reference material to encourage students to develop life-long learning skills. How early in the curriculum are journal articles introduced? This paper presents the results of a study on using a journal article in a sophomore-level class.

Chemical Engineering Progress often includes articles appropriate for use in sophomore and junior engineering science classes of thermodynamics, fluid mechanics and heat transfer ${ }^{1-6}$. These articles use only the concepts covered in the course and include analytical results with sufficient detail that they can be reproduced by the students. An ideal article leaves some variation that can be used as the basis for a design project. The Fall 2013 introductory thermodynamics course design project (Appendix 1) was based on the article Optimizing an Organic Rankine Cycle ${ }^{1}$ (OORC). The thermodynamic concepts in the paper are all covered in the course, so a student who understands the course Rankine cycle material should understand the thermodynamics of the paper. Basing the design project on the OORC paper, making the students work closely with it, is expected to increase the students' confidence in their abilities to read similar papers. Surveys were done throughout the design project to assess its effect on the students.

Methodology

The research project was conducted in an Engineering Science Introduction to Thermodynamics course with 33 students. Four students were listed as freshmen, but they were mostly likely counted as such because they had earned fewer than 30 credit hours. The remaining students were sophomores. Chemical, mechanical, and petroleum engineers all took the course.

A recruitment flyer about the research project was distributed to the students during class lecture. Those who chose to participate in the research project completed on-line surveys using the university’s Blackboard system outside of class time.

The first survey included basic demographic questions and background questions regarding the number of engineering articles they had previously read, their research experience, and confidence in their ability to read and understand an article in CEP or similar magazines for other engineering disciplines. It was thought that previous experience in reading journal article might increase a student's confidence in ability to understand the OORC article. Confidence in ability to understand the article was not defined in the surveys, but it is defined by the author as the positive feeling that one can successfully read the article, follow the thermodynamic modifications discussed, and reproduce the thermodynamic analyses.

The students were then asked to read the OORC article and answer questions about whether or not they understood it, if it was written so someone who had completed the course should be able to understand it, and how confident they were that they could understand similar-level articles 
(content survey questions). Students who did not understand the article would not be expected to feel it was written at their level. Similarly, students who did not understand the article or think it was written to their level would not be expected to be confident that they could read a similar article. The timing of the first survey was before Rankine cycles were covered in lecture, although this was delayed due to a technical difficulty.

The design project was then assigned. After the homework on Rankine cycles was due, the students were asked to reread the OORC article and again answer the content survey questions. After the design project was due, the students were asked to read the OORC article and answer the content survey questions as well as a final question about any of their other courses using a journal article that semester. Just as previous experience with journal articles might boost a student's confidence, so might an article used in another course that semester. No other surveys or assessments were done except the usual homework problems, design project, quizzes, and exams. The complete schedule is given in Table 1 , and the survey questions are given in Appendix 2.

Table 1. Schedule of classroom and research project events

\begin{tabular}{lll}
\hline Date & Classroom events & Research project events \\
\hline Oct. 18 - 23 & Rankine cycle lecture & Planned $1^{\text {st }}$ survey \\
Oct. 28 & Actual 1 ${ }^{\text {st }}$ survey \\
Oct. 30-Nov. 2 & & \\
Nov. 1 & Design project handed out & \\
Nov. 6 & Rankine cycle homework due & \\
Nov. 6 - 8 & Original project due date & $2^{\text {nd }}$ survey \\
Nov. 20 & Actual design project due date & \\
Nov. 22 & & Actual final survey \\
Dec. $4-6$ & & \\
\hline
\end{tabular}

Approval from the Institutional Review Board (IRB) for protection of human subjects was received for this project ${ }^{7}$. The project was classified as an exempt project that required only approval of the Coordinator of Research Compliance. Part of that approval was that the students completing the surveys remain anonymous: no one should be able to match a student to his response, and the primary investigator should not know which students completed a survey. As recommended by the Coordinator of Research Compliance, each student self-created an ID so his answers could be tracked through the three surveys. Although the university's Blackboard administrator assured that the survey tool is anonymous, it is not. The Grade Center includes a check mark when a student has finished a survey.

The design project was done in teams formed by the professor during the third week of the semester. The teams were made by Team-Maker ${ }^{8}$ with similar schedules and disparate GPAs. Homework assignments from that point on were done in teams. Teamwork evaluations were done by $\mathrm{CATME}^{8}$ three times during the semester, including once after the design reports were due.

No follow-up study was planned as the expected return is small. This section of thermodynamics was one of four offered Fall 2013, so the affected population is less than $25 \%$ of the sophomore 
class. The next time the author expects to teach any of these students is Spring 2015. Even then, the students from this section of Thermodynamics will be only approximately $1 / 6$ of the Spring 2015 course enrollment. With the small previously-exposed enrollment, interpretation of an effect of this study is likely to be difficult. A project based on a Chemical Engineering Progress article by Pilling and Summers on distillation column design ${ }^{9}$ may be a good follow-up to this study, particularly if a similar project is done with this year's mass transfer class as a comparison group.

\section{Results and Discussion}

No students completed the initial survey, so there are no demographics available directly from the students. Some demographics are known from the check marks in the Blackboard Grade Center.

Three students completed the second survey, and four students completed the final survey. Only one student completed both surveys, and he did not self-create the same ID both times, so no longitudinal information is available. Due to the low response rate and the inability to match responses with demographics, no demographic data will be presented. It is available upon request.

The students who completed the survey after completing the design project felt they understood the OORC article better than the students who took the survey after completing just a homework assignment on Rankine cycles, as shown in Figure 1. This was expected since the design project was based on the OORC article, and the homework was not.

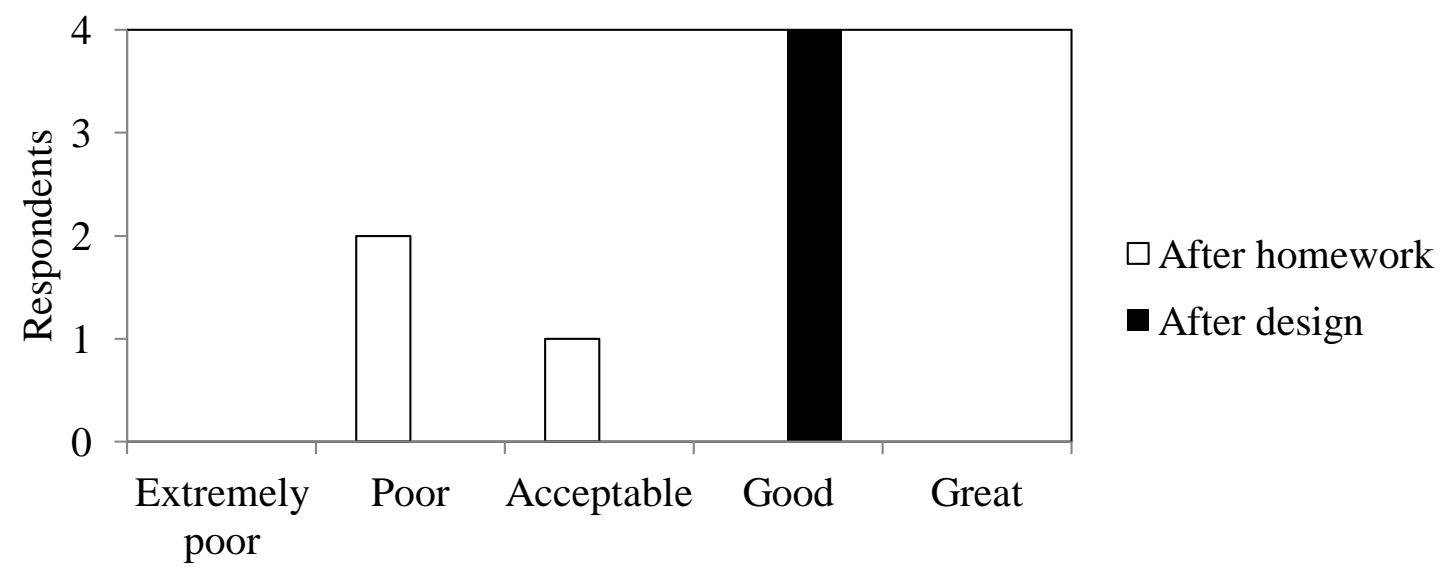

Figure 1. Students' ratings of their understanding of the OORC article.

Figure 2 presents the student responses about the level of difficulty of the OORC article. After working only the homework assignment, the students who took the survey were not sure that the article was written at a level that they should be able to understand after completing a basic thermodynamics course. After completing the project, the surveyed students did seem to think that the article was written at a level they should be able to understand after the course. This result was expected because the students were closer to having completed the course after the 
design project then they were after completing the Rankine cycle homework assignment, so they should have been better able to judge what they would understand after the course was over.

That the surveyed students better understood the article after working the design project (Figure 1) may also have influenced that they felt the article was written at their level.

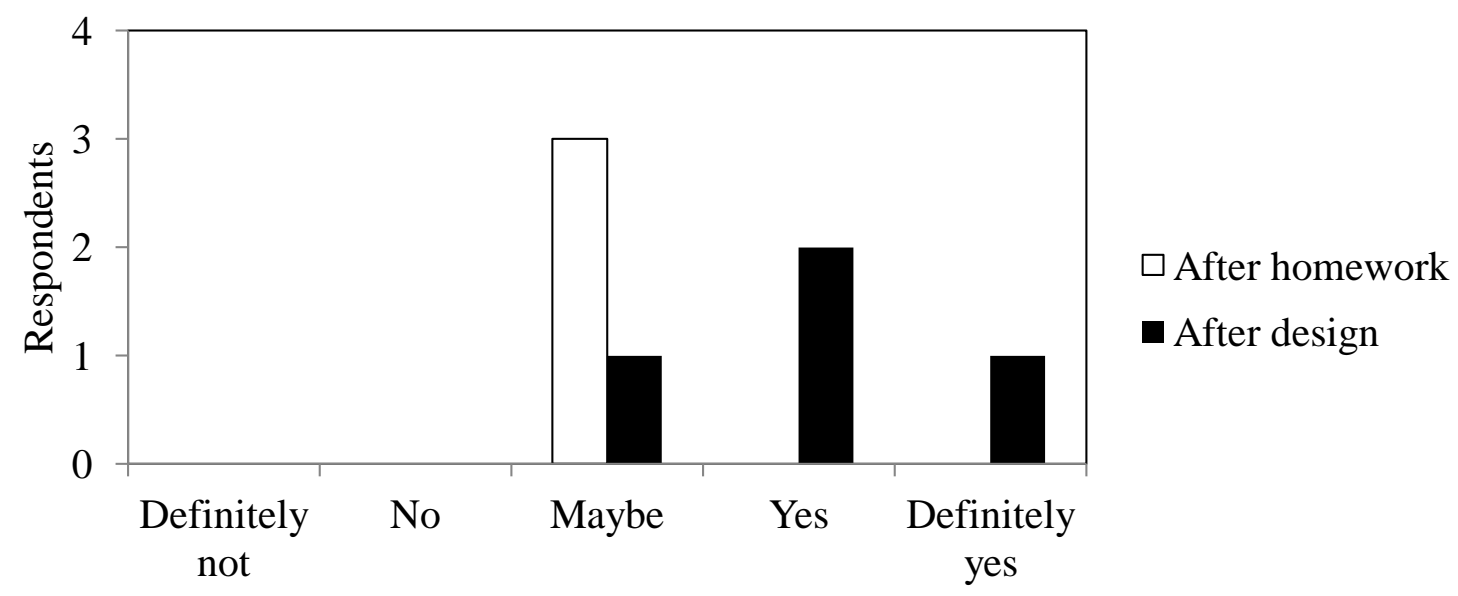

Figure 2. Student responses to "Is this article written at a level someone who has successfully completed ES 3053 can understand?"

Assigning a design project based the OORC may or may not have improved student confidence in life-long learning ability. Figure 3 shows the student responses to a question about confidence in ability to read and understand similar articles in Chemical Engineering Progress, Mechanical Engineering, or Journal of Petroleum Engineering. The results are too similar (and the responses are too few) before and after the design project to say that the design project made a difference in student confidence in life-long learning ability.

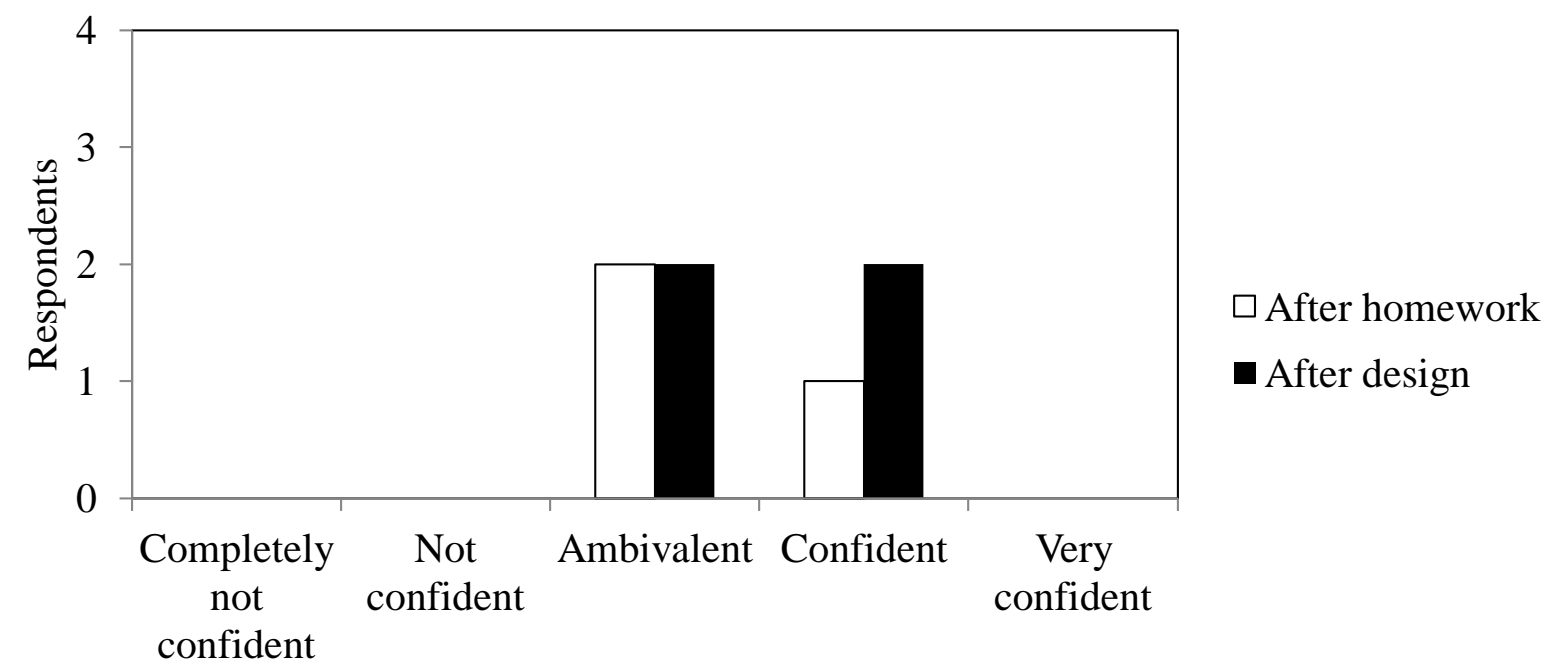

Figure 3. Student responses to "Based on this article, how confident are you that you could read and understand similar articles?" 
None of the four respondents to the final survey had another science, math, or engineering course in the Fall 2013 semester use a journal article. Without the demographic data from the initial survey, it is unknown if these sophomores had ever read an engineering journal article before the one used for this design project.

The terribly low response rate may be attributed to several possible factors:

- The initial survey was not available when the recruitment flyer was distributed. A technology mistake was made when an available time frame was set for the survey but the students were not allowed to see the research project page, which had been hidden for testing during discussions with the IRB.

- It was mentioned in class that the IRB insisted that the surveys be anonymous - that the professor should not even know if a student was participating. How were students supposed to let the professor know that there was a problem accessing the survey if he was not even supposed to know they were doing the survey? None of the 33 students in the course reported not being able to access the survey.

- The time required to read the paper and complete the survey was probably overestimated at 45 minutes for each time a student took the survey. The OORC article was only five pages long, so a shorter, more reasonable estimate may have encouraged more students to participate.

- The final survey was released later than announced on the recruitment flyer.

The surveys did not demonstrate what the primary investigator had hoped to show with this research project. It seems that the way the project was conducted contributed to its failure, and how it was conducted was partially dictated by the IRB policies. The poster will present these results but also stimulate discussion of what IRB requirements are at other universities and how this research project should have been done to gather sufficient information. Questions for discussion will include

- Do other chemical engineering faculty members seek IRB approval for similar projects?

- Whether or not publication or presentation of results is planned?

- Do the IRBs at other universities require approval for similar projects?

- Whether or not publication or presentation of results is planned?

- Do the IRBs at other universities require that respondents remain anonymous?

- Responses cannot be matched to a student?

- The professor must not know who is participating in the project?

$\circ$ Exempt versus expedited approval?

- The surveys were not done during class time due to concerns about how long it would take the students to read the OORC article and complete the surveys. Have other faculty had success using course software or on-line survey instruments?

Based on the author's understanding of the part of the Code of Federal Regulations on the protection of human subjects ${ }^{10}$, other chemical engineering faculty members should seek IRB approval for similar projects if publication is planned, and the IRBs at other universities should require such approval if publication is planned. Keeping the student responses anonymous affects whether the review is exempt or expedited, which seems to be a very small difference. Anonymous surveys are much more difficult to track longitudinally, as self-created IDs did not work in this study. Perhaps a grader or TA could collect the surveys with identifiers on them and 
code the identification before passing the surveys on to the primary investigator. This would prevent the professor from assigning mental extra credit to the students participating.

In future studies, the author will still seek IRB approval if publication or presentation of results is planned. Surveys will be done on paper during class time to minimize impediments to participation. The professor will leave the students with a grader or departmental assistant to collect the completed anonymous surveys so professor will not know who has chosen to participate in the study. These changes should greatly increase response rates while still meeting university requirements.

\section{Conclusion}

The design project in a sophomore-level introductory thermodynamics class was based on an article on organic Rankine cycles in Chemical Engineering Progress. Surveys were done after a homework assignment on Rankine cycles was due and after the design project was due. Drawing conclusions from the surveys was greatly hampered by the low number of survey responses. The four surveyed students understood the journal article better after completing the design project than the three surveyed before. Those four surveyed after the after the project were more certain that the article was written at a level they should understand after completing the thermodynamics class than the three students surveyed before the project. The two survey groups had about the same certainty that they would be able to read articles written at a similar level in the future. The problems which caused the low response rate will lead to a discussion of research techniques and requirements during the poster presentation.

Bibliography

1. A. Bourji and A. Winstead, Optimizing an Organic Rankine Cycle, Chemical Engineering Progress, January 2013, 35-39.

2. J.D. Barry, Eliminate Iteration from Flow Problems, Chemical Engineering Progress, March 2008, 36-41.

3. R.L. Shilling, Selecting Tube Inserts for Shell-and-Tube Heat Exchangers, Chemical Engineering Progress, September 2012, 20-25.

4. W. Tanthapanichakoon, Saving Energy in Multilevel Steam Systems, Chemical Engineering Progress, January 2012, 27-32.

5. R. Marshall and B. Scales, Reduce Your Compressed Air Costs, Chemical Engineering Progress, October 2011, 28-33.

6. T.G. Lestina, Selecting a Heat Exchanger Shell, Chemical Engineering Progress, June 2011, 34-38.

7. The University of Tulsa's Protection of Human Subjects Policy: http://www.utulsa.edu/research/Office-ofResearch-and-Sponsored-Programs/Research-Integrity-Compliance-and-Certification/Protection-of-HumanSubjects.aspx, accessed on March 21, 2014.

8. Team-Maker and Comprehensive Assessment of Team Member Effectiveness, catme.org, accessed February 14, 2014.

9. M. Pilling and D.R. Summers, Be Smart about Column Design, Chemical Engineering Progress, November 2012, 32- 38 .

10. Protection of Human Subjects, Code of Federal Regulations, Title 45 Part 46, 2009, http://www.hhs.gov/ohrp/humansubjects/guidance/45cfr46.html\#46.103, accessed February 14, 2014. 
Appendix 1

Design Project

To: $\quad$ ES 3053-04 Teams

From: Dr. Ford

Re: Optimizing an Organic Rankine Cycle

Date: Nov. 1, 2013

Chemical Engineering Progress, the magazine of the American Institute of Chemical Engineers, published an article on Optimizing an Organic Rankine Cycle by Ali Bourji and Alan Winstead in January $2013^{1}$. This article discusses the optimization of a Rankine cycle with propane as the working fluid. An interesting difference between a steam Rankine cycle and an organic Rankine cycle is in the high temperature heat exchanger. Since propane is supercritical in the high pressure part of the cycle, the propane does not boil in the high temperature heat exchanger, as steam does. After optimizing the simple Rankine cycle, the authors then optimize the cycle with a "recuperator", which is a variation of the regenerative cycle with a closed feedwater heater with a trap. In the regenerative cycle, a fraction of the steam is extracted at an intermediate pressure from the turbine and used to heat the fluid leaving the pump. A recuperator is the regenerative cycle in the extreme that all of the stream leaving the turbine (not at an intermediate pressure) goes to the heat exchanger with the pumped liquid. Your team's task is to design cycles with a closed feedwater heater and compare them to the cycles in the paper.

Start by verifying the work in the paper. Figure 2 states flowrates, temperatures, pressures, and qualities (vapor fractions) of the streams as well as the power and heat transfer rates. Check that their power and cycle efficiency calculations are correct. If you get discrepancies larger than $5 \%$, attempt to explain the differences.

Next, add a closed feedwater heater to the cycle in Figure 2. Your team will create one design for each team member, with a different feedwater heater pressure for each member. Use the same extraction fraction for each design. Make a graph of cycle efficiency and net power production versus feedwater heater pressure for your designs. You do not need to optimize the cycle as the article did.

Third, estimate the equivalent annual operating cost of your designs and of those in the article. Appendix A has equations for estimating capital costs, utility costs, and the equivalent annual operating cost.

Lastly, write a memo to me that discusses the project. A memo is an informal communication, such as this one, that starts with a To/From/Re/Date block at the top. Every team member should initial the From line. A suggested outline of the memo includes five paragraphs. The first paragraph should be a brief overview of the design project. Discuss whether or not you were able to verify the calculations in the article in the second paragraph. The third paragraph should cover your feedwater heater cycles and include the graph. A table of the various costs should accompany the economic discussion of the fourth paragraph. The third and fourth paragraphs might be small enough to combine. Your team should make a recommendation to construct one of the designs (original, with recuperator, or one of your feedwater heater designs) in the last 
paragraph. You should explain why you have chosen the recommended design. The body of the memo should be only 1 or 2 pages. Calculations and design diagrams should be included in the appendix. Diagrams may be hand-drawn if you use a ruler, or you may find The Engineering ToolBox Process Flow Diagram drawing template ${ }^{3}$ or Insert Shapes in Microsoft Word useful.

According to the syllabus, the design project is due Wednesday, Nov. 20. The memo will be graded according to the point distribution in Appendix B. Since writing is $50 \%$ of the grade, you may wish to take your memo to the Wallace Writing Center on the $3^{\text {rd }}$ floor of the McFarlin Library for a consultation. Tables and figures in Chapter 2 of our textbook will give you examples of proper formatting.

References

1. Ali Bourji and Alan Winstead, Optimizing an Organic Rankine Cycle, CEP, January 2013, $35-39$.

2. Fluid Mechanics, Heat Transfer, Thermodynamics Design Project: Production of Ethylbenzene, http://www.che.cemr.wvu.edu/publications/projects/\#companion, accessed Oct. 30, 2013.

3. PFD - Process Flow Diagram - Online Drawing, The Engineering ToolBox, http://www.engineeringtoolbox.com/pfd-process-flow-diagram-online-drawing-d_1640.html, accessed Oct. 31, 2013. 


\section{Appendix A \\ Cost Estimation Data ${ }^{2}$}

Note: The numbers following the attribute ( $\dot{W}=$ power, for example) are the minimum and maximum values for that attribute. For a piece of equipment with a lower attribute value than the minimum, use the minimum attribute value to compute the cost. For a piece of equipment with a larger attribute value, extrapolation is possible, but inaccurate. To err on the side of caution, you should use the price for multiple, identical smaller pieces of equipment.

Pumps $\quad \log _{10}($ purchased cost $)=3.4+0.05 \log _{10} \dot{W}+0.15\left[\log _{10} \dot{W}\right]^{2}$

$$
\dot{W}=\operatorname{power}(\mathrm{kW}, 1,300)
$$

Heat Exchangers $\log _{10}($ purchased cost $)=4.6-0.8 \log _{10} A+0.3\left[\log _{10} A\right]^{2}$

$$
\begin{aligned}
& \text { A = heat exchange area }\left(\mathrm{m}^{2}, 20,1000\right) \\
& \text { Estimate the area based on } \dot{Q}=U A \Delta T \text { with } \\
& \qquad \begin{array}{l}
\mathrm{U}=5000 \mathrm{~W} / \mathrm{m}^{2} \cdot{ }^{\circ} \mathrm{C} \text { for a feedwater heater } \\
\mathrm{U}=500 \mathrm{~W} / \mathrm{m}^{2} \cdot{ }^{\circ} \mathrm{C} \text { for the condenser } \\
\mathrm{U}=25 \mathrm{~W} / \mathrm{m}^{2} \cdot{ }^{\circ} \mathrm{C} \text { for the high temperature heat exchanger }
\end{array}
\end{aligned}
$$

Turbine $\quad \log _{10}($ purchased cost $)=2.5+1.45 \log _{10} \dot{W}-0.17\left[\log _{10} \dot{W}\right]^{2}$

$$
\dot{W}=\operatorname{power}(\mathrm{kW}, 100,4000)
$$

\section{Utility Costs}

Electricity $\quad \$ 0.06 / \mathrm{kWh}$

Cooling Water \$0.354/GJ

\section{Equipment Cost Factors}

Total Installed Cost $=$ Purchased Cost $(4+$ material factor $(\mathrm{MF})+$ pressure factor $(\mathrm{PF}))$

Pressure $<10 \mathrm{~atm}, \mathrm{PF}=0.0 \quad$ does not apply to turbines since their cost equation

(absolute) $10-20 \mathrm{~atm}, \mathrm{PF}=0.6$ includes pressure effects

$$
\begin{aligned}
& 20-40 \mathrm{~atm}, \mathrm{PF}=3.0 \\
& 40-50 \mathrm{~atm}, \mathrm{PR}=5.0 \\
& 50-100 \mathrm{~atm}, \mathrm{PF}=10
\end{aligned}
$$

Carbon Steel $\mathrm{MF}=0.0$

Stainless Steel MF $=4.0$

The Equivalent Annual Operating Cost (EAOC, \$/y), is defined in Equation 1.

$$
E A O C=0.20 C A P+A O C-R
$$

CAP $(\$)$ is the total installed cost for the pump, heat exchangers, and the turbine,

AOC (\$/y) is the annual operating cost, which is the utility cost for the condenser, and

$\mathrm{R}(\$ / \mathrm{y})$ is the annual revenue or savings from the electricity generated.

The factor 0.20 includes a $15 \%$ rate of return on investment and a ten-year plant life. 


\section{Appendix B \\ Design Project Gradesheet}

Team

Members:

Writing (generally -1 point per error)

/ 5 Spelling

/ 5 Grammar

/ 5 Flow/logical connectedness/clarity

/ 5 Proper content in proper places (Appendix material in appendix, etc.)

/ 5 Formatting (Is it a memo? Table labeled? Graph labeled? Etc.)

$125 \quad$ Writing Total

Technical

$/ 7$ Article verification

18 Regenerative designs

/ 8 Economic analysis

12 Recommendation

$/ 25$ Technical Total

I50 Project Total

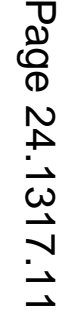


Appendix 2

Survey Questions

Self-created ID questions - asked in each survey

1. What is the first letter of your oldest pet's name? Use $\mathrm{N}$ if you don't have a pet.

2. What is the last digit of your youngest sibling's age? Use 0 if you don't have a sibling.

3. What is the first letter in the name of your favorite band?

4. What is the last digit of the month for your mother's birthday?

Initial Demographics Survey - asked only in the initial survey

1. How many articles have you read from the following?

Chemical Engineering Progress (AIChE's magazine)

Mechanical Engineering (ASME's magazine)

Journal of Petroleum Technology (SPE's magazine)

2. How confident are you that you can read an article in one of the magazines above and understand it?

Completely not confident, not confident, ambivalent, confident, very confident

3. Have you done any research at the college level?

If so, for how many months?

How many journal articles related to your research have you read, and what journals were they in?

4. Have any of your previous science, math, or engineering courses used a journal article as part of the course material?

If so, please list the journals and courses.

5. Gender: Male, Female

6. Major: Chemical Engineering, Electrical Engineering, Engineering Physics, Mechanical Engineering, Other, Petroleum Engineering

7. Level: Freshman, Sophomore, Junior, Senior

8. Semester at TU: $1,2,3,4,5,6,7,8,9$ or more

Content Survey - asked in each survey

Read the article, which is aimed at BS-level working chemical engineers. When you have completed ES 3053, you should have all of the thermodynamics required to understand this article.

1. Rate your understanding of the article

Extremely poor, poor, acceptable, good, great

2. Is this article written at a level someone who has successfully completed ES 3053 can understand?

Definitely not, no, maybe, yes, definitely yes

3. Based on this article, how confident are you that you could read and understand similar articles in Chemical Engineering Progress, where this article was printed, or similar articles in Mechanical Engineering or Journal of Petroleum Technology?

Completely not confident, not confident, ambivalent, confident, very confident

One additional question for the last survey: 
1. Have any of your science, math, or other engineering courses this semester used a journal article as part of the course material? If so, please list the journals and courses.

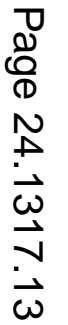

